\title{
Middle Childhood
}

National Cancer Institute

\section{Source}

National Cancer Institute. Middle Childhood. NCI Thesaurus. Code C89347.

A human life stage that begins at six years of age and continues until eleven complete years of age. 